\title{
One Health: Towards safeguarding the health, food security and economic welfare of communities
}

\author{
Author: \\ David Nabarro ${ }^{1}$ \\ Affiliation: \\ ${ }^{1}$ Special Representative of \\ the United Nations Secretary \\ General for Food Security \\ and Nutrition \\ Correspondence to: \\ David Nabarro \\ Email: \\ musoket@arc.agric.za \\ Postal address: \\ 2 UN Plaza Room 2613, New \\ York 10017, USA \\ How to cite this preface: \\ Nabarro, D., 2012, 'One \\ Health: Towards safeguarding \\ the health, food security \\ and economic welfare of \\ communities', Onderstepoort \\ Journal of Veterinary \\ Research 79(2), Art. \#450, \\ 3 pages. http://dx.doi. \\ org/10.4102/ojvr.v79i2.450 \\ Note: \\ Proceedings of the \\ Conference of the Southern \\ African Centre for Infectious \\ Disease Surveillance 'One \\ Health' held at the National \\ Institute for Communicable \\ Diseases, Johannesburg, July \\ 2011.
}

C 2012. The Authors. Licensee: AOSIS OpenJournals. This work is licensed under the Creative Commons Attribution License.
It is a privilege for me to be invited to join this conference organised by young African scientists who are exploring the opportunities for integrated approaches to animal and human health. Thank you for inviting me.

In my early professional assignments I worked with communities in Southeast Asia and East Africa. I sensed that their food systems, patterns of agriculture, nutrition and health were inextricably linked. Their leaders often told me that dealing with a range of different professionals was intensely frustrating and what they needed was multi-skilled professionals who really understood the challenges people face. They need to appreciate how rural life and livelihoods vary from season to season, or change over the years as climatic conditions, access to infrastructure or new initiatives by government or civil society alter the environment in which people live and work.

In my presentation today I shall focus on ways in which the 'One Health' approach is contributing to food security and economic well-being of communities as well as helping to safeguard their personal health. I appreciate that you have been discussing these issues in depth in the last two days: I hope that you will share your observations with me.

\section{One Health thinking}

One Health is a way of thinking that reflects the reality of people's lives and livelihoods. That thinking encourages a focus on new kinds of outcomes, policies, actions and research agendas different from those which will be pursued if we stay within our normal professional disciplines.

One Health thinking, outcomes, policies, action and research are important for:

- increasing the number of people who enjoy food security - who have stable access to nutritious foods for their needs

- ensuring bio-secure and ecologically sustainable production of safe food for people to eat

- encouraging accessible local markets and fair international trade in agricultural products.

The risk of disease emergence at the interface between animals, humans and ecosystems is at the current core of One Health thinking. It can include illnesses that have an indirect effect on human health through their impact on people's livelihoods ... and the drivers that increase the risk of emerging diseases (climate change, resource depletion, land degradation, demand, lack of biosecurity, contamination).

We should not try to define One Health thinking and action too tightly. Please do not see one health as a scientific discipline or international programme. Instead let us look at how different stakeholders - in government, amongst farmers and food processors, within consumer groups and civil society - use the concepts in practice.

\section{A serious global food security situation}

We face a global situation where an estimated 925 million people go hungry. The effects of recent food price increases are likely to deepen the vulnerability of those who spend between $50 \%$ and $80 \%$ of their family budget on food, mostly basic staples.

Efforts to respond to food insecurity, food safety and food trade challenges have addressed all four dimensions of food security namely, availability, access, utilisation and stability. Progress has been made at several levels such as:

- countries affected by food insecurity

- investors in countries' efforts to improve food security

- the organisations that support both countries and investors and

- the system for governance of international arrangements to assist affected countries (including the revitalised Committee on Food Security). 
Rising prices present a great opportunity for farmers to respond to growing demand. But farmers need inputs and cash to do this. They need help to manage the risks associated with trying to produce more. And they need the infrastructure to market their food. Well-functioning food markets and trade have huge potential to increase small farmers' integration into value chains so as to increase the benefits they can capture from the trade in their products.

\section{Drivers for animal disease}

Farmers seeking to increase their livestock holdings have particular challenges. They can find themselves facing outbreaks of disease in their animals: these might contribute to the emergence of infectious disease emergence at the human-animal-ecosystem interface.

The livestock sector is an area in which One Health thinking and action can make a difference to lives and livelihoods. Estimates from the World Bank on the projection for the increase in meat production over the next 40 years indicate that most of this will occur in the developing world. Improving livestock production in a sustainable and humane manner that balances both carbon and water footprints is a major challenge facing the One Health community.

For the $75 \%$ of the world's poor that are rural and dependent on agriculture, disease outbreaks in livestock not only put at risk their immediate food source, but it also puts at risk their livelihoods and resilience capacity - and that affects their long-term food security.

Disease outbreaks which reduce the availability of live animals and livestock products can reduce household income, undermine the diets of household members, impair nutritional status and increase risks to health, especially of women and children. Outbreaks can also impair the wider market availability for those products. Chronic food insecurity also drives risky behaviours related to animals: no one who is well-fed would consider consuming the carcass of an animal that has died of disease.

Effects of animal disease extend to people who work in production and processing - including livestock and agrifood workers, transporters and sellers. One Health thinking helps us find ways to limit these risks and encourage resilient livelihoods.

Agricultural intensification and lack of biosecurity can also result in food borne disease: The WHO (World Health Organisation) estimates that in 1997, food contamination cost up to $\$ 35$ billion in the United States alone due to medical costs and lost productivity.

Fear of losing business can also result in further disease spread in a clandestine way. The potential negative economic impacts of restricting the movement and sale of diseased animals or animal products (a common response to disease emergence) may unfortunately drive some linked to the industry to try to work around bans on sales and trade in order to maintain their income - and in the process, potentially extends a disease outbreak and makes it harder to control.

\section{The World Bank has calculated that:}

The emergence of BSE, SARS, H5N1, and influenza A(H1N1) have caused over US\$20 billion in direct economic losses over the last decade and much more than US\$200 billion in indirect losses.

\section{Better food security and food safety through One Health principles}

In the UN (United Nations) system we seek coordinated responses to food insecurity and unsafe food through movements of multiple actors. These encourage a broad range of stakeholders to work in synergy as they pursue immediate and longer term food security outcomes. The work goes best if undertaken under the leadership of national authorities. We focus on multi-disciplinary and multi-stakeholder movements, anchored to institutions but not controlled by them.

We also encourage multi-stakeholder platforms where different groups work together and coordinate support particularly for smallholder-based food security initiatives and nutrition-sensitive agricultural development. We have developed a Comprehensive Framework for Action (CFA) for food security and a Road Map for Scaling up Nutrition (SUN) to guide the emergence of these movements.

What have we learnt over the past few years in applying one health thinking to food and nutrition security, food safety, markets and trade?

- Firstly, the need for country leadership: Effective action to ensure food security and safe food for all happens if led from within countries.

- Secondly, the need for clarity on results: In our work the emphasis has been on equitable and sustained improvements in people's lives, long-term health and resilient livelihoods.

- Thirdly, the need for joint working: by institutions which tend to function separately. These include government services - and their ministries - with separate responsibilities for animal and human health, the environment, as well as for agriculture and trade.

- Fourthly, the value of being inclusive: working with and responding to stakeholders outside government particularly organisations of smallholder farmers and those who work in the livestock val ue chain, businesses, agriculture unions, consumers' organisations, local food producers.

\section{Putting One Health thinking into practice}

Government Ministers expect us bureaucrats and professionals to advise them on how best to avoid risk 
associated with disease at the animal-human-ecosystem interface. We have made real progress in the area of H5N1 Highly Pathogenic Avian Influenza, and in relation to SARS and spongiform encephalopathy. But we have much more to do with regard to sustainable livelihoods of pastoral communities, rabies, or what some refer to as the forgotten zoonoses. I know that you have been discussing some of these in your meeting.

I am keen to see One Health thinking become a central feature for responsible national and international policy making. This means putting the lessons we have learnt into practice:

- Firstly, never forgetting that our primary clients are those most at risk of food insecurity or most likely to be affected by unsafe food or market failure.

- Secondly, working together for sensible and realistic policies to improve food and nutrition security, sustainable and bio-secure production, safe livestock products, functioning markets and fair trade.

- Thirdly, overcoming our tendency to work in our professional niches and bureaucratic silos, and instead sharing data and analyses, developing joint policies, doing research together, implementing joint investigations and being accountable for delivering results. It helps if we undergo training together, too.

- Fourthly, focusing on outcomes that have meaning to the business community, to human health, animal welfare and wildlife advocates, to politicians and to the media and then working hard to demonstrate and communicate our results.

Within the UN system our Secretary General advocates for comprehensive, and increasingly integrated responses to the current challenges we face in the health, food and agriculture, climate change and trade interface. He encourages broadbased partnerships that focus on results. He requires our different organisations to work together and to link up with governments, regional organisations, private companies, civil society and - most importantly - farmers' organisations. He wants us to explain the virtues of working in a joined up way and of breaking down professional silos. Only then can we contribute to safeguarding the health, food security and economic prospects of poor communities.

We have seen real progress in the African Union especially with pastoral communities and in the work being done by FAO (Food and Agriculture Organisation), $\mathrm{WHO}$ and the OIE (Office of International Education). We are delighted to see the emergence of multi-disciplinary networks of professionals dedicated to supporting equity, reducing poverty and encouraging resilient livelihoods. We are pleased that young professionals like you are taking responsibility for working effectively at interfaces in ways that respond to people's realities. You listen to the people you serve, to each other, to politicians and other stakeholders and to your own instincts as you take this important work forward. You are helping to build trust and respect between people and professionals, between different professional disciplines and between departments and organisations. You are impatient for results so you try to work in synergy rather than in competition. You appreciate what matters to people rather than spending time telling them what they should do - or feel.

Much more needs to be done. Here are my requests to you today:

- Please continue to work in ways that reflect One Health thinking and action.

- Please look for opportunities to advocate for One Health in national parliaments, regional assemblies and globally; with farmers' organisations, labour unions and civil society groups; with businesses and entrepreneurs.

- Please do what you can to inspire wider and stronger networks of people who are excited by the potential of effective one-health working that empowers communities to act in ways that improve health and livelihoods.

- Please contribute to the growing movement for One Health that works in the service both of poor communities and of the global good, brings together women and men, farmers and consumers as well as social and physical scientists, and engages all nations. 